\title{
Exosomes: secreted vesicles and intercellular communications
} Clotilde Théry

Address: Institut Curie, INSERM U932, Paris, France

Email: clotilde.thery@curie.fr

FI000 Biology Reports 20II, 3:I5 (doi:I0.34I0/B3-15)

This is an open-access article distributed under the terms of the Creative Commons Attribution-Non Commercial License (http://creativecommons.org/licenses/by-nc/3.0/legalcode), which permits unrestricted use, distribution, and reproduction in any medium, provided the original work is properly cited. You may not use this work for commercial purposes.

The electronic version of this article is the complete one and can be found at: http://fl000.com/reports/b/3//5

\begin{abstract}
Exosomes are small membrane vesicles of endocytic origin secreted by most cell types, and are thought to play important roles in intercellular communications. Although exosomes were originally described in 1983, interest in these vesicles has really increased dramatically in the last 3 years, after the finding that they contain mRNA and microRNA. This discovery sparked renewed interest for the general field of membrane vesicles involved in intercellular communications, and research on these structures has grown exponentially over the last few years, probing their composition and function, as well as their potential value as biomarkers.
\end{abstract}

\section{Introduction}

Secreted vesicles known as exosomes were first discovered nearly 30 years ago. But, considered little more than cellular garbage cans acting to discard unwanted molecular components, exosomes remained little studied for the next 10 years. Over the past few years, however, evidence has begun to accumulate that the vesicles are like signaling payloads containing cell-specific collections of proteins, lipids, and genetic material that are transported to other cells where they alter function and physiology. The findings have reignited interest in exosomes, but also more generally in all secreted vesicles, whether they can be called exosomes or not, and the topic has now blossomed into a full-fledged field of research-that of vesicle-modulated cell-cell communication.

Two years ago, I began receiving daily emails regarding my articles on exosomes, requesting reprints, details on exosome-related protocols, and advice on the purification and characterization of the vesicles. Having worked in this area for more than 10 years, I thought I knew all the other researchers working on the subject, but the requests were coming in from groups I hadn't heard of before. The flood of inquiries made me realize that the field had been growing, attracting the attention of more and more researchers in a relatively short period of time.
A quick glance at the literature confirmed the trend: while fewer than 20 PubMed-referenced papers using the word "exosomes" were published in early 2003, and just over 60 in 2007, nearly 350 exosome studies have been published in the last 3 years alone. The idea thus came to me and to Graça Raposo, who discovered exosomes from immune antigen-presenting cells in 1996, to organize an International Workshop on Exosomes (IWE). Although a meeting organized by the late Rose Johnstone, who participated in the first description of exosomes in 1983, had drawn 25 scientists to Montreal, Canada, in 2005 [1], the new meeting, which took place this January at our home institution, the Curie Institute in Paris, attracted nearly 10 times as many attendees. There, researchers discussed their recent findings on exosomes, and on other types of secreted membrane vesicles, in fields ranging from immunology to neurobiology and tumor biology, as well as potential clinical applications, such as biomarkers or as therapeutic tools.

In pluricellular organisms, cells communicate with each other via extracellular molecules such as nucleotides, lipids, short peptides, or proteins. These molecules are released extracellularly by cells and bind to receptors on other cells, thus inducing intracellular signaling and modification of the intracellular physiological state of the recipient cells. But, in addition to these single molecules, 
eukaryotic cells also release in their extracellular environment complex structures called membrane vesicles, which contain numerous proteins, lipids, and even nucleic acids, and can affect the cells that encounter these structures in much more complex ways. Although known to exist for several decades (for instance, in blood, where they are generally called "microparticles", or in seminal fluid, where they are called "prostasomes" [2]), membrane vesicles have long been thought of as mere cell debris, signs of cell death, or structures very specific to a unique organ. The phenomenon of exosomes and their wider involvement in intercellular signaling began to emerge from this picture in the last decade.

Exosomes represent a specific subtype of secreted membrane vesicles (reviewed in [3]). Exosomes are formed in endosomal compartments called multivesicular endosomes, containing internal vesicles that package and store molecules in membrane-bound structures. Endosomes are generally considered to function as an intermediate compartment between the plasma membrane, where endocytosis of extracellular molecules takes place, and compartments (lysosomes), where these molecules are released and degraded. However, about 25 years ago, the groups of Philip Stahl [4] in the United States and Rose Johnstone in Canada [5] described, using very elegant pulse-chase and electron microscopy experiments, that in reticulocytes undergoing maturation into red blood cells, multivesicular late endosomes could fuse back with the plasma membrane (instead of with lysosomes), and release their contents, including numerous small vesicles, extracellularly. In 1987, the term "exosomes" was proposed to define these extracellularly released intra-endosomal vesicles [6].

Exosomes remained all but forgotten for the next 10 years until Raposo, while working with the group of Hans Geuze in Holland in 1996 [7], showed that Epstein-Barr virus (EBV)-transformed B-lymphocytes secreted exosomes that bore molecules essential for the adaptive immune response: major histocompatibility class (MHC) II dimers bound to antigenic peptides. These exosomes were also shown to present the MHC-peptide complexes to specific $\mathrm{T}$ cells, suggesting that they could play a role in adaptive immune responses. Two years later, the groups of Raposo, Amigorena, and Zitvogel [8] demonstrated that dendritic cells (the immune cells that initiate adaptive immune responses by presenting MHC-peptide complexes to naïve $\mathrm{T}$ cells) also secrete exosomes bearing functional MHCpeptide complexes, which could promote induction of antitumor immune responses in mice in vivo. These results provided the basis for the hypothesis that exosomes could play an active role in intercellular communication, at least in the immune system, and prompted the very first attempt at using them in the clinic, as a new type of anticancer therapy in humans. (After phase I trials held between 1999 and 2002, a phase II trial is currently ongoing at the Gustave Roussy Institute (with participation of the Curie Institute) in France [9].)

The first major advance of subsequent years was linked to the development of large-scale protein analysis techniques, which allowed us to demonstrate that exosomes represent a specific subcellular compartment, rather than random cell debris. Proteomic analyses of exosome composition were first performed on exosomes secreted by dendritic cells $[10,11]$, and then on exosomes from numerous other different cell types, which are compiled in the ExoCarta compendium [12]. These studies showed that exosomes did not contain a random array of the intracellular proteins, but a specific set of a few protein families, essentially coming from the plasma membrane, endocytic pathway, and the cytosol, with very limited amounts of proteins from other intracellular compartments (e.g., nucleus, endoplasmic reticulum, and Golgi apparatus), which made them clearly different from membrane vesicles released by apoptotic cells. These results established that exosomes are actively secreted by live cells, and confirmed their intra-endosomal origin. In parallel, studies of exosomes purified in vitro from tissue cultures (of immune cells but also epithelial and tumor cells), started showing that exosomes secreted by one cell could be captured by another cell and transfer information to the latter. The information transferred could include antigens or MHC-peptide complexes for increasing the range of antigen-presenting cells and the efficiency of induction of immune responses [13-15], or in some cases negative signals leading to death of the target cell [16]. These observations provide the basis of the nowadays popular idea that exosomes represent a new type of intercellular messenger.

The second real breakthrough in this field came in 2007, with the convincing description by the group of Jan Lötvall in Sweden of the presence of mRNA and microRNA (miRNA) inside these vesicles [17]. In addition, the authors showed, at least in vitro using large amounts of concentrated exosomes, that some mRNA present in exosomes could be translated into proteins in target cells, suggesting that exosomes can transfer genetic information. This discovery, and the concomitant development of research on miRNAs, sparked the recent exponential increase in the numbers of papers on exosomes.

In January 2011, oral and poster presentations at the IWE 2011 covered all the currently explored fields of exosome research spanning immunology and cell biology, their use as biomarkers, and their relationship to tumors. 
This led to very open and constructive discussions. My four major conclusions from this meeting are that: (a) exosomes are not the only secreted membrane vesicles that could act as intercellular messengers, and efforts should be dedicated to combine and compare data obtained on these different vesicles; (b) the next few years should show us whether RNA and miRNA in circulating vesicles (exosomes or others) will prove to be useful biomarkers of various diseases, providing new diagnostic or prognostic tools; (c) although they were originally described in cells of the immune system, exosomes are now known to be secreted by many different cell types, and a large amount of recent data highlight their possible functions as messengers during development of tumors, in some functions of stem cells, in the nervous system, or during interactions of pathogens with their host; (d) although the last 3 decades have expanded our knowledge of exosomes considerably, there is still no definite evidence for their physiological functions in vivo, and demonstrating such functions remains a major challenge of this field.

\section{Exosomes and other secreted membrane vesicles}

The term "exosomes" should be used to define secreted membrane vesicles that form inside intracellular multivesicular compartments and that are released upon fusion of these compartments with the plasma membrane (Figure 1). Because of this intracellular origin, exosomes

Figure I. Exosome basics

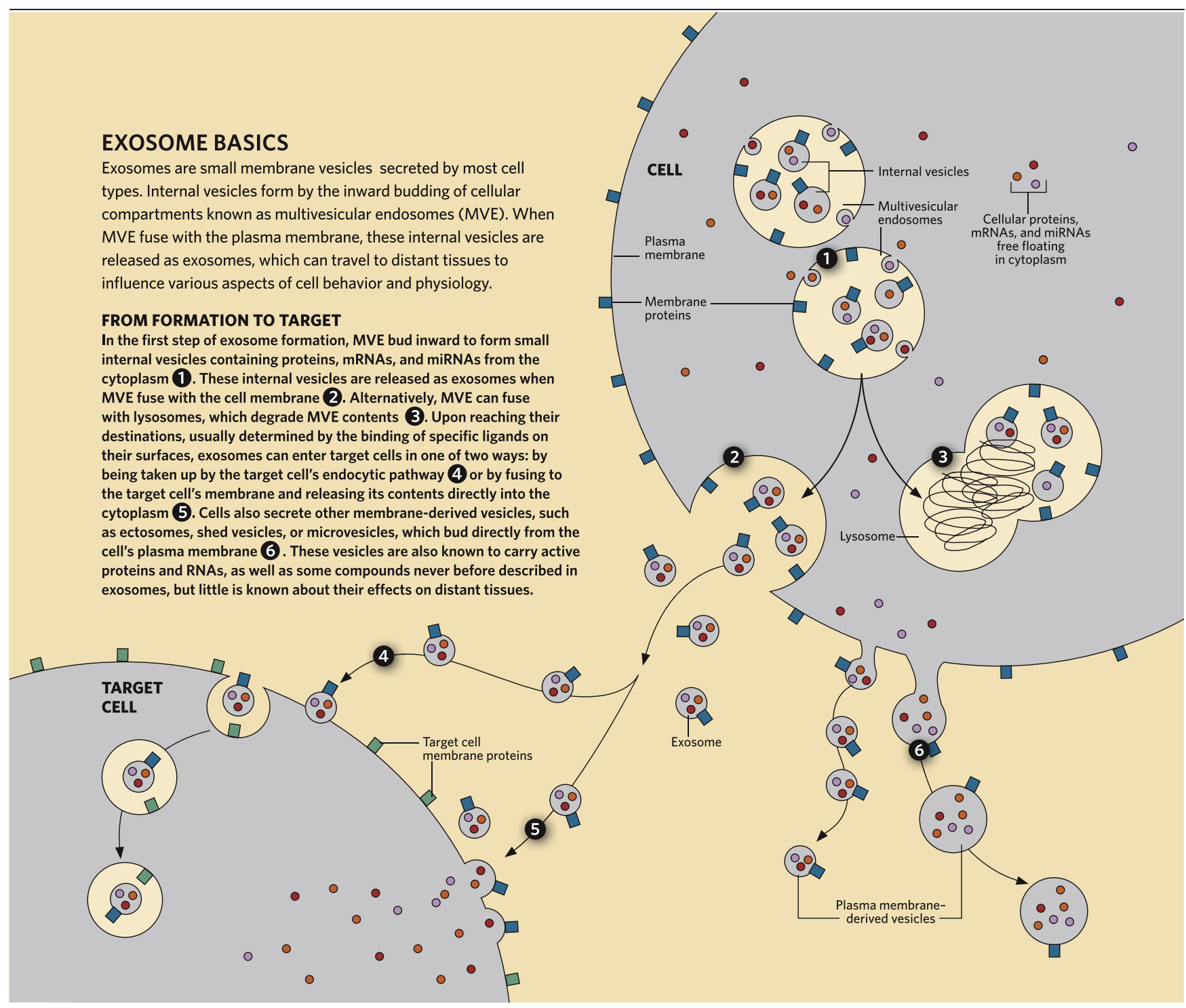


are similar in size to internal vesicles of multivesicular compartments; that is, around $100 \mathrm{~nm}$ in diameter. Exosomes are commonly purified on the basis of size by serial steps of centrifugation, with a final 100,000 g ultracentrifugation to pellet exosomes; however, this purification is not absolute. Some cells also release other types of membrane vesicles, which can, for instance, directly bud off the plasma membrane towards the outside of the cell. The size of such vesicles is not as strictly determined as that of exosomes, and they can be anywhere between $50-1,000 \mathrm{~nm}$ in diameter. Various terms have been used for these vesicles, such as "ectosomes" [18], "shed vesicles", or "microvesicles", but this latter term has also been used more widely for any type of vesicle, whether intra- or extracellular, and regardless of its intracellular origin. The release of large plasma membrane-derived vesicles is quickly induced after stimuli such as fresh fetal calf serum on tumor cells [19], complement deposition, or increasing intracellular $\mathrm{Ca}^{2+}$ in neutrophils [20]. Vesicles can be separated by size using ultracentrifugation at different speeds, with the larger vesicles pelleting at lower speed than the smaller ones. But similarly sized vesicles of different intracellular origins (i.e., exosomes and small plasma membrane-derived vesicles) will not be separated by this method. Flotation of vesicles on sucrose gradients can allow some separation of vesicles with different densities, but this separation is not complete. Thus, adequate means to distinguish the different types of vesicles secreted by a cell are still lacking.

Proteomic studies of microvesicles or ectosomes have not, so far, been as extensive as for exosomes, but they are underway and they will help to understand the specificity of their secretion. Like exosomes, membrane microvesicles and ectosomes contain various active molecules, such as cytokines, growth factor receptors, and RNAs, and also metalloproteases (which have not been described in exosomes), but since studies comparing exosomes and other vesicles released by the same cells are only beginning now, understanding the functional specificity of each type of vesicle should become possible in the next few years.

\section{RNA and miRNA in secreted membrane vesicles}

Since the identification of RNA in exosomes in 2007 and development of high-throughput techniques for nucleic acid analyses, there have been an ever increasing number of studies reporting sequences of the RNA in exosomes. Such studies show that not all messenger RNAs present in a cell end up in exosomes, and there is apparently specific targeting of some mRNA sequences into the released vesicles [17]. These last observations refute the idea that mRNA in exosomes results from a random contamination of secreted vesicles by mRNA released extracellularly by dying cells. However, it is still unclear from the few published studies whether one can (as for exosomal proteins) find a set of exosomal mRNA that would be consistently targeted to exosomes in any cell type, possibly in addition to cell type-specific mRNA sequences. Understanding the mechanisms of mRNA targeting to these vesicles should open the way to understanding the function of RNA delivery to secreted vesicles. Of note, mRNA has also been described in microvesicles (or mixed exosome/microvesicle preparations) released by tumors or embryonic stem cells [21-23], and some ongoing studies are now comparing sequences of RNA targeted to either exosomes or larger vesicles, and determining whether there is a distinct targeting to each of them.

The situation is even more complicated for miRNA: even though they have also been observed in various exosome preparations, the heterogeneity of techniques used to identify the miRNA sequences do not allow one to conclude whether there is specific targeting of miRNA to secreted vesicles. In addition, although extracellular release of miRNA can be decreased by some drugs, the literature still describes heterogeneous results concerning the respective contribution of free (or protein-associated) miRNA, as compared to miRNA encapsulated in exosomes or other secreted membrane vesicles.

Despite the uncertainties about the nature of mRNA and miRNA-carrying vesicles, the biopharma industry has put a lot of effort into studying the use of secreted vesiclesespecially their mRNA and miRNA content-as biomarkers in clinics. This is easier than it might seem to be because their encapsulation into membrane vesicles protects extracellular RNAs from degradation, and allows efficient recovery from biological fluids, such as plasma, urine, milk, sperm, or saliva. Work in several different laboratories to compare RNA (as well as protein) sequences in vesicles isolated from normal and cancer cell lines, for instance, and from biological fluids of patients (cancer or other diseases) is ongoing. It is still too early to propose new biomarkers (either for diagnosis, prognosis, or predictive response to therapies) from these studies, but given the current effort put in this direction, the next few years should allow us to decide whether such markers exist and are useful.

\section{Proposed functions of exosomes}

Once secreted, membrane vesicles interact with surrounding cells: many fluorescence microscopy studies show capture of these vesicles and accumulation in internal endocytic or phagocytic compartments, especially in phagocytic cells such as macrophages, but one must keep in mind that vesicles smaller than $200 \mathrm{~nm}$ in 
diameter cannot be detected by confocal microscopy techniques, and only electron microscopy allows detailed visualization of exosomes. Hence, the way individual vesicles interact with recipient cells is still not known, and has been proposed to involve binding at the cell surface via specific receptors, internalization by endocytosis or micropinocytosis, and/or fusion with plasma membrane or with the limiting membrane of internal compartments. Evidence that fusion does occur in certain cases comes from a recent study showing diffusion of exosomal lipids in the membrane of recipient cells [24]: this observation explains how exosomes could release their internal content (e.g., RNA) into the cytosol of recipient cells.

Exosomes induce physiological changes in recipient cells upon interaction. Because the original description of exosomes was in immune cells, there is a vast amount of data on the immunological effects of exosomes, and these vary strongly depending on the physiological state of the cells which secrete them (see [9] for references). For instance, mature dendritic cells secrete exosomes that carry antigens or MHC-peptide complexes, and induce antigen-specific immune responses by other dendritic cells (especially in the context of anticancer therapies); conversely, exosomes secreted by dendritic cells subjected to immunosuppressive treatments, or modified to express immunosuppressive cytokines, can instead promote tolerogenic immune responses, which could make them useful as a treatment for autoimmune diseases. In a third example, macrophages infected with procaryotic mycobacteria release exosomes that, depending on the mycobacteria strain, bear antigens and promote immune responses (nonpathogenic strain), or inhibit macrophage activation and cytokine secretion, thus dampening immune response (pathogenic strain).

Although exosomes secreted by tumor cells carry antigens from the secreting tumors and can be captured and used to present tumor antigens by dendritic cells, they also bear various immunosuppressive molecules, which can inactivate $\mathrm{T}$ lymphocytes or natural killer cells, or promote the differentiation of regulatory $\mathrm{T}$ lymphocytes or myeloid cells (which suppress immune responses). The net result of these contradictory effects in vivo is not yet established, and although several groups defend the hypothesis that tumors secrete exosomes to promote their growth by inhibiting antitumor immune responses, or by promoting angiogenesis or migration outside the tumor bed to form metastases, this has not been proved. Still, it has been suggested that depletion of membrane vesicles from the blood circulation of patients could be used as an anticancer treatment [25], but I would be cautious in using such approaches in the absence of proper understanding of what tumor-derived exosomes or other membrane vesicles do in vivo. An alternative explanation is that membrane vesicles of tumor origin in the circulation of cancer patients could simply be the result of tumor expansion, rather than a sign of active involvement of these vesicles in tumor progression.

Other tissues or cells secrete exosomes bearing immunosuppressive molecules: placenta-derived vesicles, which bear ligands for natural killer lymphocytes, are found in pregnant women's blood circulation, and extensive analyses of components of these vesicles are underway to identify their role in the mother's tolerance to the fetus. Depending on the state of the host, exosomes (or vesicles) present in their bronchoalveolar fluid can bear tolerizing molecules (e.g., in mice tolerized for an allergen) or, conversely, increase proinflammatory cytokine secretion by airway epithelial cells (in asthmatic human patients). Secretion of exosomes by eukaryotic parasites (Leishmania major) or pathogens (such as fungi) has also been recently described. It is thought to contribute to tolerance of the host for the parasite by dampening immune response or, conversely, to contribute pathologic inflammatory reactions of the host to the pathogen.

In addition to the immune system, exosomes probably affect other physiological functions. Exosomes are secreted by neural, epithelial, muscle, and stem cells, and their range of proposed functions is extensive. Exosomes from mesenchymal stem cells contribute to tissue repair of host cardiac tissue, and, conversely, lung tissue can release exosomes (or possibly other vesicles) that modify stem cells to promote differentiation of the lung tissue into lung epithelial cells $[26,27]$. Exosomes also contribute to communication within the nervous system. Exosomes are secreted by neurons, oligodendroglial cells, and microglia, and exosomes from each source can affect other neural cells [28-30]. Exosomes are involved in the formation/transfer of pathogenic proteins (such as prions and amyloid deposits) [31,32]. No doubt other functions will appear in the coming years!

\section{Physiological functions of exosomes}

Despite the amount of data on what exosomes (and other secreted membrane vesicles) can do in vitro, or in vivo when injected into animals, all data discussed above were obtained with vesicles purified and concentrated in vitro from cell culture supernatants or from biological fluids, so it is not clear whether these processes occur under physiological conditions. The main problem is that the efficiency of the purification and quantification procedures is unknown. It is likely that ultracentrifugation does not allow $100 \%$ recovery of the vesicles secreted at any given time, and that part of the secreted vesicles are 
even inaccessible to purification because they are recaptured by cells rather than released in the culture medium or fluid, so it is very difficult to know whether the amounts of membrane vesicles used to observe the effects described above correspond to physiological amounts secreted in vivo, or not. Indeed, there remains a nagging question in the exosome field as to whether they actually have any physiological functions in vivo.

Answering this question requires tools to inhibit or increase exosome secretion specifically, without affecting secretion of other membrane vesicles, or affecting general secretion of proteins or lipid mediators. Several groups are currently trying to identify such tools, especially by deciphering the molecular mechanisms involved in formation of intracellular vesicles of multivesicular compartments, and in the fusion of these compartments with the plasma membrane. Several molecules have been shown to affect exosome secretion, although in the absence of means to visualize and quantify actual fusion of multivesicular endosomes with the plasma membrane in real time, it is still difficult to know whether they are involved specifically in this final step, or at another stage of the endocytic pathway. A consensus has not yet been reached on the molecular mechanisms involved. Indeed, depending on the cell types, different molecules have been described in the biogenesis and secretion of exosomes: Rab11 in erythroleukemia cell lines [33], Rab27 in Hela cells [34], and Rab35 and neutral sphingomyelinase in oligodendroglial cells $[35,36]$. It remains to be determined whether these discrepancies are due to different machineries used in different cell types, and/or whether the secreted vesicles analyzed in the different studies come from different intracellular compartments (along the endocytic pathway, or even outside this pathway). Recent studies showing that internal vesicles of multivesicular endosomes can, in some circumstances, form without the help of the ESCRT (endosomal sorting complex required for transport) machinery (described as being responsible for segregation of molecules into internal vesicles of late endosomes in yeast) suggest that, indeed, more types of multivesicular compartments than initially thought may coexist in the same cells, and may possibly lead to different types of exosomes. In any case, targeting one or the other of these molecules to affect exosome secretion will require careful evaluation of the consequences (in terms of exosomes, but also other secretions) in each different model system analyzed. Other approaches to address the physiological functions of exosomes in vivo, proposed during the meeting in Paris, include generating exosomes with modified expression of a given functional protein and analyzing their functional outcome, or containing bacterial enzymes to identify target cells via measurement of the enzymatic activity. Using these approaches in genetically modified mice will be the next step for this challenging field.

Finally, similar cell biology studies on the generation of other secreted membrane vesicles are also underway, and hopefully will allow proper discrimination of the roles as messengers of the different types of vesicles.

\section{Conclusion}

With the amazing expansion of the number of published studies on exosomes in the last 3 years, it is clear that research on secreted membrane vesicles and their roles as intercellular messengers is now a very exciting field, with new ideas, hypotheses, and questions coming up faster than answers! The IWE in Paris allowed most of the longterm exosome and vesicle aficionados, as well as many of the newcomers, to meet, exchange ideas freely, and to point out current problems with technologies, definitions, and characterization. The meeting ended with the decision to prolong this very productive workshop by setting up future yearly meetings, virtual spaces to record exchanges and discussions (such as a website and/or a Facebook page), and a scientific society dedicated to exosomes and secreted membrane vesicles. Some of these are already underway, with the next IWE tentatively scheduled for April 2012, a Facebook page already up and running [37], a website for comparison of protein and RNA composition of exosomes already set up [38], and the rest hopefully coming soon. We strongly encourage the readers of this article to check these web links $[37,38]$ to follow the next steps of this emerging scientific world.

\section{Abbreviations}

IWE, International Workshop on Exosomes; MHC, major histocompatibility class; miRNA, microRNA.

\section{Competing interests}

The authors declare that they have no competing interests.

\section{Acknowledgements}

CT apologizes to all the IWE participants whose work she could not clearly cite in this short article, and thanks INSERM, Institut Curie, Fondation de France, Institut National du Cancer (INCa), and Agence Nationale de la Recherche (ANR) for support of her research.

\section{References}

I. Couzin J: Cell biology: The ins and outs of exosomes. Science 2005, 308: 1862-3.

2. Ronquist G, Brody I: The prostasome: its secretion and function in man. Biochim Biophys Acta 1985, 822:203-18.

3. Théry $C$, Ostrowski M, Segura E: Membrane vesicles as conveyors of immune responses. Nat Rev Immunol 2009, 9:58I-93. 
4. Harding C, Heuser J, Stahl P: Receptor-mediated endocytosis of transferrin and recycling of the transferrin receptor in rat reticulocytes. J Cell Biol 1983, 97:329-39.

FI000 Factor 8

Evaluated by Clotilde Théry 20 Jun 2011

5. Pan BT, Teng K, Wu C, Adam M, Johnstone RM: Electron microscopic evidence for externalization of the transferrin receptor in vesicular form in sheep reticulocytes. J Cell Biol I985, 101:942-8.

FI000 Factor 8

Evaluated by Clotilde Théry 20 Jun 2011

6. Johnstone RM, Adam M, Hammond JR, Orr L, Turbide C: Vesicle formation during reticulocyte maturation. Association of plasma membrane activities with released vesicles (exosomes). J Biol Chem 1987, 262:94I2-20.

7. Raposo G, Nijman HW, Stoorvogel W, Liejendekker R, Harding CV, Melief CJ, Geuze HJ: B lymphocytes secrete antigen-presenting vesicles. J Exp Med 1996, I83:1 161-72.

8. Zitvogel L, Regnault A, Lozier A, Wolfers J, Flament C, Tenza D, Ricciardi-Castagnoli P, Raposo G, Amigorena S: Eradication of established murine tumors using a novel cell-free vaccine: dendritic cell-derived exosomes. Nat Med 1998, 4:594-600.

FI000 Factor 8

Evaluated by Clotilde Théry 20 Jun 2011

9. Chaput N, Théry C: Exosomes: immune properties and potential clinical implementations. Semin Immunopathol 20II, [Epub ahead of print]

10. Théry C, Boussac M, Véron P, Ricciardi-Castagnoli P, Raposo G, Garin J, Amigorena S: Proteomic analysis of dendritic cellderived exosomes: a secreted subcellular compartment distinct from apoptotic vesicles. I Immunol 200I, 166:7309-18.

II. Théry C, Regnault A, Garin J, Wolfers J, Zitvogel L, RicciardiCastagnoli P, Raposo G, Amigorena S: Molecular characterization of dendritic cell-derived exosomes. Selective accumulation of the heat shock protein hsc73. J Cell Biol 1999, I47:599-6I0.

12. Mathivanan S, Simpson RJ: ExoCarta: A compendium of exosomal proteins and RNA. Proteomics 2009, 9:4997-5000.

13. Théry $C$, Duban L, Segura E, Véron $P$, Lantz $O$, Amigorena S: Indirect activation of naïve CD4+ $T$ cells by dendritic cell-derived exosomes. Nat Immunol 2002, 3:1 I56-62.

FI000 Factor 6

Evaluated by Stella C Knight 20 Nov 2002

14. Wolfers J, Lozier A, Raposo G, Regnault A, Théry C, Masurier C, Flament C, Pouzieux S, Faure F, Tursz T, Angevin E, Amigorena S, Zitvogel L: Tumor-derived exosomes are a source of shared tumor rejection antigens for CTL cross-priming. Nat Med 200I, 7:297-303

15. Karlsson M, Lundin S, Dahlgren U, Kahu H, Pettersson I, Telemo E: "Tolerosomes" are produced by intestinal epithelial cells. Eur J Immunol 200I, 3 I:2892-900.

16. Andreola G, Rivoltini L, Castelli C, Huber V, Perego P, Deho P, Squarcina P, Accornero P, Lozupone F, Lugini L, Stringaro A, Molinari A, Arancia G, Gentile M, Parmiani G, Fais S: Induction of lymphocyte apoptosis by tumor cell secretion of FasL-bearing microvesicles. J Exp Med 2002, 195: I303-16.

FI000 Factor 8

Evaluated by Glenn Dranoff 30 May 2002

17. Valadi H, Ekström K, Bossios A, Sjöstrand M, Lee لl, Lötvall JO: Exosome-mediated transfer of mRNAs and microRNAs is a novel mechanism of genetic exchange between cells. Nat Cell Biol 2007, 9:654-9.

FI000 Factor 13

Evaluated by Jeff Coller 22 May 2007, Robert Parton 20 Jun 2007, Etienne Joly 02 Jul 2007, Alain Ghysen 04 Jul 2007
18. Stein JM, Luzio JP: Ectocytosis caused by sublytic autologous complement attack on human neutrophils. The sorting of endogenous plasma-membrane proteins and lipids into shed vesicles. Biochem J 199I, 274:38I-6.

19. Cassarà D, Ginestra A, Dolo V, Miele M, Caruso G, Lucania G, Vittorelli ML: Modulation of vesicle shedding in 870 I BC human breast carcinoma cells. J Submicrosc Cytol Pathol 1998, 30:45-53.

20. Hess C, Sadallah S, Hefti A, Landmann R, Schifferli JA: Ectosomes released by human neutrophils are specialized functional units. J Immunol 1999, 163:4564-73.

21. Skog J, Würdinger T, van Rijn S, Meijer DH, Gainche L, SenaEsteves M, Curry WT Jr, Carter BS, Krichevsky AM, Breakefield XO: Glioblastoma microvesicles transport RNA and proteins that promote tumour growth and provide diagnostic biomarkers. Nat Cell Biol 2008, 10:1470-6.

22. Baj-Krzyworzeka M, Szatanek R, Weglarczyk K, Baran J, Urbanowicz B, Brański P, Ratajczak MZ, Zembala M: Tumourderived microvesicles carry several surface determinants and mRNA of tumour cells and transfer some of these determinants to monocytes. Cancer Immunol Immunother 2006, 55:808-I8.

FI000 Factor 6

Evaluated by Clotilde Théry 20 Jun 201 I

23. Ratajczak J, Miekus K, Kucia M, Zhang J, Reca R, Dvorak P, Ratajczak MZ: Embryonic stem cell-derived microvesicles reprogram hematopoietic progenitors: evidence for horizontal transfer of mRNA and protein delivery. Leukemia 2006, 20:847-56.

FI000 Factor 10

Evaluated by Etienne Joly 0I Nov 2006

24. Parolini I, Federici C, Raggi C, Lugini L, Palleschi S, De Milito A, Coscia C, lessi E, Logozzi M, Molinari A, Colone M, Tatti M, Sargiacomo M, Fais S: Microenvironmental pH is a key factor for exosome traffic in tumor cells. J Biol Chem 2009, 284:342 I I-22.

FI000 Factor 8

Evaluated by Clotilde Théry 20 Jun 2011

25. Ichim TE, Zhong Z, Kaushal S, Zheng X, Ren X, Hao X, Joyce JA, Hanley HH, Riordan NH, Koropatnick J, Bogin V, Minev BR, Min WP, Tullis RH: Exosomes as a tumor immune escape mechanism: possible therapeutic implications. J Transl Med 2008, 6:37.

26. Lai RC, Arslan F, Lee MM, Sze NS, Choo A, Chen TS, Salto-Tellez M, Timmers L, Lee CN, El Oakley RM, Pasterkamp G, de Kleijn DP, Lim SK: Exosome secreted by MSC reduces myocardial ischemia/reperfusion injury. Stem Cell Res 2010, 4:214-22.

FI000 Factor 6

Evaluated by Terry Elton I8 Mar 20II

27. Quesenberry PJ, Aliotta JM: The paradoxical dynamism of marrow stem cells: considerations of stem cells, niches, and microvesicles. Stem Cell Rev 2008, 4:137-47.

28. Potolicchio I, Carven GJ, Xu X, Stipp C, Riese RJ, Stern LJ, Santambrogio L: Proteomic analysis of microglia-derived exosomes: metabolic role of the aminopeptidase CDI3 in neuropeptide catabolism. J Immunol 2005, I 75:2237-43.

FI000 Factor 6

Evaluated by Clotilde Théry 20 Jun 201 I

29. Krämer-Albers EM, Bretz N, Tenzer S, Winterstein C, Möbius W, Berger H, Nave KA, Schild H, Trotter J: Oligodendrocytes secrete exosomes containing major myelin and stress-protective proteins: Trophic support for axons? Proteomics Clin Appl 2007, I:|446-6I.

FI000 Factor 6

Evaluated by Clotilde Théry 20 Jun 2011

30. Lachenal G, Pernet-Gallay K, Chivet M, Hemming FJ, Belly A, Bodon G, Blot B, Haase G, Goldberg Y, Sadoul R: Release of exosomes from 
differentiated neurons and its regulation by synaptic glutamatergic activity. Mol Cell Neurosci 20I I, 46:409-18.

FI000 Factor 6

Evaluated by Clotilde Théry 20 Jun 2011

31. Fevrier B, Vilette D, Archer F, Loew D, Faigle W, Vidal M, Laude H, Raposo G: Cells release prions in association with exosomes. Proc Natl Acad Sci U S A 2004, 101:9683-8.

FI000 Factor 6

Evaluated by Clotilde Théry 20 Jun 2011

32. Rajendran L, Honsho M, Zahn TR, Keller P, Geiger KD, Verkade P, Simons K: Alzheimer's disease beta-amyloid peptides are released in association with exosomes. Proc Natl Acad Sci U S A 2006, I03: I II72-7.

FI000 Factor 6

Evaluated by Clotilde Théry 20 Jun 2011

33. Savina A, Fader CM, Damiani MT, Colombo MI: Rab I I promotes docking and fusion of multivesicular bodies in a calciumdependent manner. Traffic 2005, 6:131-43.

FI000 Factor 6

Evaluated by Clotilde Théry 20 Jun 2011

34. Ostrowski M, Carmo NB, Krumeich S, Fanget I, Raposo G, Savina A, Moita CF, Schauer K, Hume AN, Freitas RP, Goud B, Benaroch P,
Hacohen N, Fukuda M, Desnos C Seabra MC Darchen F, Amigorena S, Moita LF, Théry C: Rab27a and Rab27b control different steps of the exosome secretion pathway. Nat Cell Biol 2010, I 2:19-30.

35. Trajkovic K, Hsu C, Chiantia S, Rajendran L, Wenzel D, Wieland F, Schwille $P$, Brügger $B$, Simons $M$ : Ceramide triggers budding of exosome vesicles into multivesicular endosomes. Science 2008 , 319:1244-7.

FI000 Factor 14

Evaluated by Harald Stenmark 05 Mar 2008, Paul Roche 10 Mar 2008, Gerrit van Meer 28 Mar 2008, Linda Huang II Apr 2008, Clotilde Théry 20 Jun 2011

36. Hsu C, Morohashi Y, Yoshimura S, Manrique-Hoyos N, Jung S, Lauterbach MA, Bakhti M, Grønborg M, Möbius W, Rhee J, Barr FA, Simons M: Regulation of exosome secretion by Rab35 and its GTPase-activaitng proteins TBCIDIOA-C. J Cell Biol 2010, 189:223-32.

FI000 Factor 6 Evaluated by Clotilde Théry 20 Jun 201 I

37. Facebook Group - Exosomes, microvesicles and other secreted vesicles. [http://www.facebook.com/\#!//home.php?sk= group_|7|22958292 |487]

38. ExoCarta - Exosome protein and RNA database. [http:// exocarta.ludwig.edu.au/] 